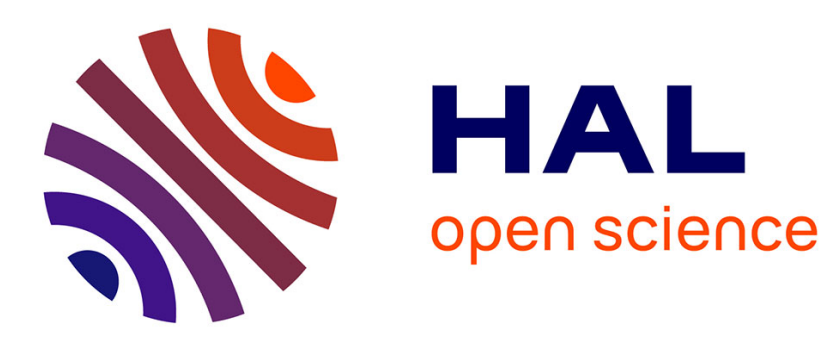

\title{
Laser-induced fluorescence spectra of the non symmetrical isotopomers of $\mathrm{CuCl} 2$
}

\author{
A. Bouvier, E. Bosch, J. Coste
}

\section{To cite this version:}

A. Bouvier, E. Bosch, J. Coste. Laser-induced fluorescence spectra of the non symmetrical isotopomers of $\mathrm{CuCl} 2$. Journal de Physique IV Proceedings, 1994, 04 (C4), pp.C4-767-C4-770. 10.1051/jp4:19944210 . jpa-00252673

\section{HAL Id: jpa-00252673 https://hal.science/jpa-00252673}

Submitted on 1 Jan 1994

HAL is a multi-disciplinary open access archive for the deposit and dissemination of scientific research documents, whether they are published or not. The documents may come from teaching and research institutions in France or abroad, or from public or private research centers.
L'archive ouverte pluridisciplinaire HAL, est destinée au dépôt et à la diffusion de documents scientifiques de niveau recherche, publiés ou non, émanant des établissements d'enseignement et de recherche français ou étrangers, des laboratoires publics ou privés. 


\title{
Laser-induced fluorescence spectra of the non symmetrical isotopomers of $\mathrm{CuCl}_{2}$
}

\author{
A.J. BOUVIER, E. BOSCH and J.C. COSTE
}

Laboratoire de Spectrométrie Ionique et Moléculaire, URA 171 du CNRS, Université Lyon I, Bât. 205, 43 Bd du 11 Novembre 1918, 69622 Villeurbanne cedex, France

\begin{abstract}
Investigations of the ground state of $\mathrm{CuCl}_{2}$ have been pursued recording laser induced fluorescence spectra on a BOMEM DA3 Fourier transform spectrometer in the range $10000-16500 \mathrm{~cm}^{-1}$. In this work, we specially extend the study to the non symmetrical isotopomers ${ }^{35} \mathrm{Cl}^{63} \mathrm{Cu}^{37} \mathrm{Cl}$ and ${ }^{35} \mathrm{Cl}^{65} \mathrm{Cu}^{37} \mathrm{Cl}$. Band-by-band and polynomial fits allowed us to determine rotational and vibrational constants in the range $v " 1=0-9, v^{\prime \prime} 3=0-6$ that will be compared to the constants of the main symmetrical isotopomers ${ }^{63} \mathrm{Cu}^{35} \mathrm{Cl}_{2}$. An approximate Valence Force Field model is tested and discussed.
\end{abstract}

\section{Introduction}

$\mathrm{CuCl}_{2}$ is one of the simplest molecule to be found among the transition metal dihalides and is a good candidate for testing ligand field theory on d electron systems. After a few works, thirty years ago /1/, recently this molecule became again very attractive. First, the ab initio calculations of Bauschlicher and Roos $/ 2 /$ was a useful framework for the spectroscopic exploration of this molecule. Then, Yoshida $3,4 /$ suggested that this molecule was responsible of very st ong red and infra-red emissions during a chemical reaction with ener ${ }_{5} y$ transfer between $\mathrm{O}_{2}^{1} \Delta_{\mathrm{g}}, \mathrm{Cl}_{2}$ and heated copper $\left(200^{\circ} \mathrm{C}\right)$. This molecule has also another chemical interest for the formation of polyvinylchloride $/ 5 \%$

In several contributions $/ 6,7 /$ we presented a high resolution spectroscopic study of the ground state of $\mathrm{CuCl}_{2}$ using the combined Fourier Transform Spectrometry (F.T.S) and Laser Induced Fluorescence (L.I.F) techniques. The last paper. /7/ gave a global treatement for the four symmetrical isotopomers of copper dichloride, assuming a Valence Force Field linear $\mathrm{XY}_{2}$ molecule model for isotopic shifts. A simple polynomial expression for the $v_{1}, v_{3}$ and $J$ rovibrational levels of the observed ground state allowed to obtain a complete set of molecular parameters, force constants and $\mathrm{Cu}-\mathrm{Cl}$ bond length.

In this work, we try to extend the study to the non symmetrical isotopomers of $\mathrm{CuCl}_{2}$. In natural $\mathrm{CuCl}_{2}$, their abundance is respectively $25.14 \%$ and $11.83 \%$. Obtaining extensive data proved difficult and the data base is still reduced. However, we will give our preliminary results. We have determined the effective 
spectroscopic constants for the two states ${ }^{2} \Pi_{\mathfrak{u}}$ and $\mathrm{X}^{2} \Pi_{g 3 / 2}$ of the red transition using band-by-band fit. Then, we separately used polynomial expressions for vibrational and rotational energies to obtain their inherent constants. We took ${ }^{63} \mathrm{Cu}^{35} \mathrm{Cl}_{2}$ as a test molecule to verify the simplified Valence Force Field model relative to the non symmetrical isotopomers $/ 8 /$.

\section{Experiments}

The sources are sealed quartz cells containing copper wire and enough $\mathrm{Cl}_{2}$ to react stoichiometrically to produce $\mathrm{CuCl}_{2}$. The cells are ended by two Brewster windows to minimize the reflection of the laser polarized light, and equipped with a sidearm. A cell is heated in a dual temperature electric oven. For isotopic studies of the non symmetrical molecule, we need to use natural $\mathrm{CuCl}_{2}$. To increase rotational relaxation processes, we can introduce a few torrs of argon before sealing. The fluorescence of $\mathrm{CuCl}_{2}$ is excited with a CW ring dye laser (Spectra Physics 380-D), pumped by an argon ion laser, operating single mode with DCM, Rh6G or Kiton Red dye. The laser mode is monitored by a $2 \mathrm{Ghz}$ confocal interferometer and for high resolution, a reference extra-cavity of 500MHz, free spectral range, (Spectra Physics 388) is used. Backwards, L.I.F. is collected and focused into a fused silica optical fiber. L.IF. arrives to the entrance iris of the Micheison interferometer (BOMEM DA3). The spectra are recorded using a silicon avalanche detector. A Fizeau wavemeter controls continuously the laser wavelength. An optical filter is used to attenuate the laser line and protect the detector. The access to the anti-Stokes side of the L.I.F. spectrum is possible when the level of scattered light from the ring laser is low enough. The spectrum is recorded at low resolution $\left(30 \mathrm{~cm}^{-1}\right)$ to choose accuratly the laser wavelength; then, we record the spectrum at high resolution $\left(0.070 \mathrm{~cm}^{-1}\right):$ a good compromise between convenient recording time ( 2 hours) and the Doppler width of $\mathrm{CuCl}_{2}$.

\section{Results}

The spectra we obtained are illustrated in figure 1. Several isotopes are present and it is generally the case for all the spectra recorded with a good signal to noise ratio. The wavenumber of any fluorescence line can be represented by a difference in term energies for the upper and lower electronic states:

$$
v_{\text {measured }}=T^{\prime} v^{\prime}\left(J^{\prime}\right)-T_{v_{1} v_{3}}(J)
$$

Figure 1

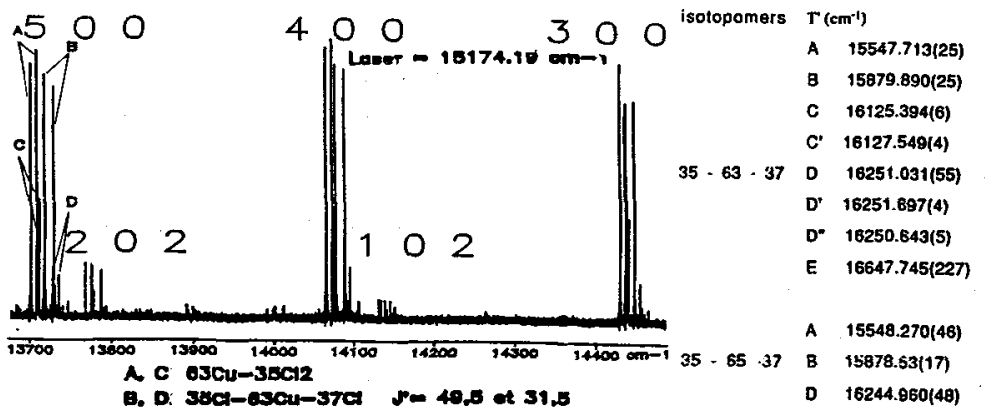

Table I

$\begin{array}{ll}B^{\prime}\left(\mathrm{cm}^{-1}\right) & D^{\prime}\left(\mathrm{cm}^{-1}\right) .10^{-} \\ 0.050521(16) & 7.9(2) \\ 0.050353(17) & 7.5(2) \\ 0.049882(11) & 7.0 \\ 0.049882 & 7.0 \\ 0.049882 & 7.0 \\ 0.04920(3) & 7.0 \\ 0.0482 & 7.0 \\ 0.0542(1) & 7.0 \\ & \\ 0.050485(22) & 10.5 \\ 0.05047(9) & 22(1) \\ 0.049889(21) & 10.0\end{array}$


where, $\quad T^{\prime} v^{\prime}\left(J^{\prime}\right)=T^{\prime} v^{\prime}+B^{\prime} v^{\prime} J^{\prime}\left(J^{\prime}+1\right)-D^{\prime} v^{\prime} J^{\prime 2}\left(J^{\prime}+1\right)^{2}$,

is the total vibration energy populated by the iaser and $\mathrm{J}^{\prime}$ the rotational quantum number of the $2 \Pi_{\mathrm{u}}$ state. For the ground state, we used a similar expression The table I shows the complexity of the $2 \Pi_{\mathfrak{u}}$ state. We cannot assign a vibrational numbering. The tables II and III present the effective rovibrational constants obtained using a band-by-band fit for $\mathrm{X}^{2} \Pi_{\mathrm{g}} 3 / 2$ state for ${ }^{35} \mathrm{Cl}^{63} \mathrm{Cu}^{37} \mathrm{Cl}$ and ${ }^{35} \mathrm{Cl}^{65} \mathrm{Cu}^{37} \mathrm{Cl}\left(0 \leq v "{ }_{1} \leq 9\right.$ and $\left.0 \leq v "{ }_{3} \leq 6\right)$. The R.M.S. deviation of the global fit is generally of a few $10^{-3} \mathrm{~cm}^{-1}$ except for perturbed vibrational levels, for example $\left(v{ }_{1}=8-9, v{ }_{3}=0\right),\left(v{ }_{1}=5, v{ }_{3}=2\right)$. Using these accurate results we take separate polynomial developments function of $v_{1}, v_{2}$ and $v_{3}$ for $G\left(v_{1}, v_{2}, v_{3}\right), B\left(v_{1}, v_{2}, v_{3}\right)$ and $D\left(v_{1}, v_{2}, v_{3}\right)$.

$$
\begin{aligned}
& G\left(v_{1}, v_{2}, v_{3}\right)=\sum_{j=1,2,3} \omega_{j}\left(v_{j}+d_{j} / 2\right)+x_{11}\left(v_{1}+1 / 2\right)^{2}+x_{33}\left(v_{3}+1 / 2\right)^{2}+x_{13}\left(v_{1}+1 / 2\right)\left(v_{3}+\right. \\
&1 / 2)+x_{111}\left(v_{1}+1 / 2\right)^{3}+x_{113}\left(v_{1}+1 / 2\right)^{2}\left(v_{3}+1 / 2\right)+x_{133}\left(v_{1}+1 / 2\right)\left(v_{3}+1 / 2\right)^{2}+x_{333}\left(v_{3}+1 / 2\right)^{3} \\
& B\left(v_{1}, v_{2}, v_{3}\right)=B_{e}-\Sigma_{j=1,2,3} \alpha_{j}\left(v_{j}+d_{j} / 2\right) \\
& D\left(v_{1}, v_{2}, v_{3}\right)=-D_{e}-\Sigma_{j=1,2,3} \beta_{j}\left(v_{j}+d_{j} / 2\right)
\end{aligned}
$$

The bending vibration did not appear or appeared so weakly that we neglected the terms including $\omega_{2}$. We obtained spectroscopic constants using a least squares fitting code MINUIT /9/ (table IV).

\begin{tabular}{|c|c|c|c|c|c|c|}
\hline${ }^{65} \mathrm{a} \cdot{ }^{-1}$ & ${ }^{\prime 3}$ & $\operatorname{Tr}(c)-1)$ & $B=\left(c \sigma^{-1}\right)$ & $D^{\prime \prime}\left(10^{-9}=0^{-1}\right)$ & Motine & R.M.MS $\left(\mathrm{cm}^{-1}\right)$ \\
\hline 1 & 0 & $962.983(n)$ & $005645(F)$ & 100 & 2 & 0,001 \\
\hline 2 & 0 & $726.11(4)$ & $0.05641(2)$ & $18(2)$ & 7 & 0,003 \\
\hline 3 & 0 & $1088.68(9)$ & $0.05617(4)$ & $5,2(4,0)$ & B & 0,004 \\
\hline 4 & 0 & $1449.79(3)$ & $0.056120(15)$ & $12,4(1,5)$ & 10 & 0,007 \\
\hline 5 & 0 & $1809,96(2)$ & $0.00605(1)$ & $18,20(12)$ & 14 & 0,006 \\
\hline 6 & 0 & $2169,38(2)$ & $0.05860(14)$ & $8,4(2)$ & 10 & 0,002 \\
\hline 7 & 0 & $2527,27(14)$ & $0.05594(6)$ & $36,8(11,2)$ & 12 & 0.087 \\
\hline 8 & 0 & $2844,22(3)$ & $0.0592(2)$ & $90,3(2,9)$ & 10 & 0.019 \\
\hline 0 & 2 & 1026,097 & $0,05613(2)$ & $10,0(1)$ & 4 & 0.012 \\
\hline 1 & 2 & $1385,03(3)$ & $0.056120(16)$ & $15,7(1,9)$ & 14 & e.008t \\
\hline 2 & 2 & $1743,24(4)$ & $\operatorname{ans} 605(2)$ & $19,4(3,3)$ & 10 & 0.0037 \\
\hline 3 & 2 & $2100,64(3)$ & $0,055860(9)$ & 10,0 F) & 8 & 0.008 \\
\hline 4 & 2 & $2456,17(3)$ & $0,05511(4)$ & $57,1(8,1)$ & 8 & 0.017 \\
\hline 5 & 2 & $2311.63(3)$ & $0,05587(2)$ & $34,70,0)$ & 8 & 0,019 \\
\hline 6 & 2 & $3165,80(3)$ & $0.05576(2)$ & $36,6(3,3)$ & 6 & 0.014 \\
\hline 7 & 2 & $3519,62(5)$ & $0,05537(9)$ & $10.0(5)$ & 4 & 0,0039 \\
\hline 8 & 2 & $3872,06(1)$ & $0.05515(F)$ & $23,7(6)$ & 4 & 0.0076 \\
\hline 0 & 4 & $2043,184(3)$ & $0,0559(\%)$ & $10(F)$ & 2 & 0.0032 \\
\hline 1 & 4 & $2397,22(4)$ & $0.05608(2)$ & $52,9(3.3)$ & 8 & 0.021 \\
\hline 2 & 4 & $2750.61(3)$ & $0.05596(2)$ & $51.6(2.6)$ & 8 & 0.017 \\
\hline 3 & 4 & $3102,95(3)$ & $0,05 s 83(2)$ & $51,0(3,0)$ & 8 & 0,019 \\
\hline 2 & 6 & $3751,14(1,58)$ & $0.0551(3)$ & lo:o(t) & 5 & 0.61 \\
\hline 3 & 6 & $4103.3(8)$ & $0.0541(2)$ & $10.0(\mathrm{AP})$ & 6 & 0.36 \\
\hline 4 & 6 & $4436.99(1,97)$ & $0.0569(4)$ & $10.0(n)$ & 5 & 0.2 \\
\hline 5 & 6 & $4781.8(2,0)$ & $0.0570(5)$ & $10,0(\mathrm{f})$ & 4 & 0.2 \\
\hline
\end{tabular}

Table II

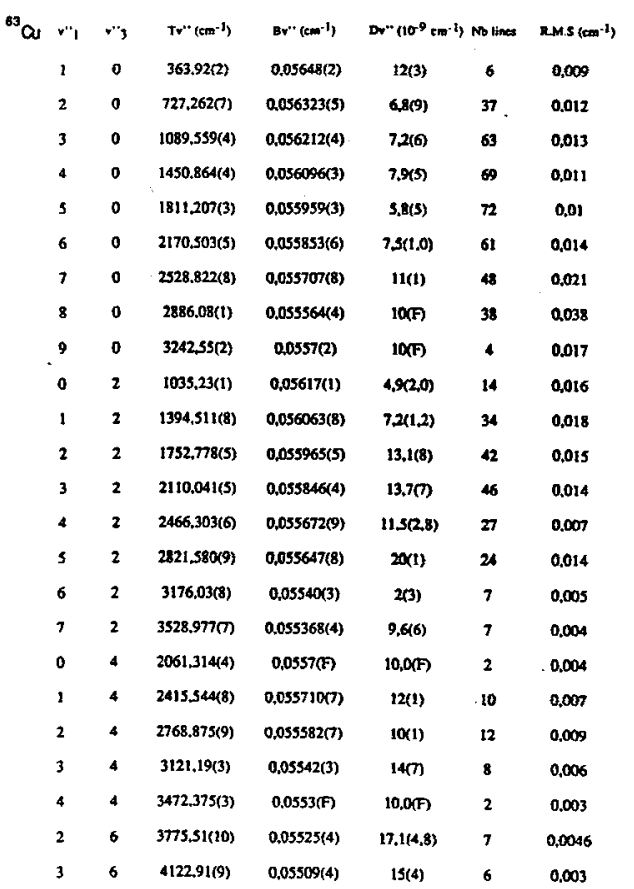

Table III

\section{Discussion}

In table $\mathrm{V}$ we compared the main constants $\mathrm{B}_{\mathrm{e}}, \omega_{1}, \omega_{3}$ with constants of ${ }^{63} \mathrm{Cu}^{35} \mathrm{Cl}_{2}$ previously determined $/ 7 /$. For non symmetrical, $\mathrm{CuCl}_{2}$ the moment of inertia has been calculated for two hypothesis : the copper is not superposed to the center of mass and is equidistant from the two different chlorines; we found a 
good agreement between the ratio of the constants $\mathrm{B}_{e}$ and of moments of inertia. Formulae for the isotopic effect in unsymmetrical linear triatomic molecules, assuming a small mass difference, might be available because $\left(\Delta \mathrm{m}_{\mathrm{y}} / \mathrm{m}_{\mathrm{y}}\right)^{2}=0.003 \ll<1$ in our case $/ 10 \%$. In fact the agreement is good enough for $\Delta \omega_{1} / \omega_{1}$ but not satisfying for $\Delta \omega_{3} / \omega_{3}$.

Table IV

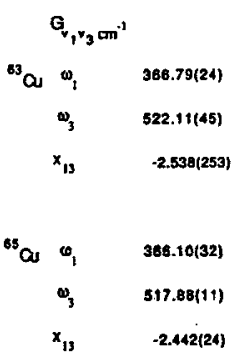

$$
B_{v, v_{3}} c m^{-1}
$$$$
\text { B. } 5.6715(38) .10^{-2}
$$$$
a_{1} \quad 1.1621(531) .10^{-4}
$$$$
\alpha_{3} \quad 1.8626(752) .10^{4}
$$

$$
D_{v_{1}, 3}
$$$$
\text { D. } 1.1(9) .10^{-8}
$$$$
\text { B. } 0.75(1.3) \cdot 10^{-9}
$$$$
\text { B } 0.16(19) .10^{4}
$$

B. $\operatorname{sen}(4) \cdot 10^{-2}$

a. $1.00(29) \cdot 10^{-1}$

$a_{3} \quad 1.67(27) \cdot 10^{-4}$
Table V

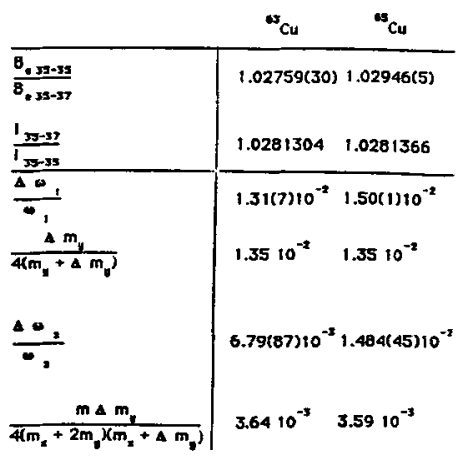

\section{Conclusion}

Resuts concerned the ground state of the two non symmetrical isotopomers of $\mathrm{CuCl}_{2}$.Effective spectroscopic constants have been determined for all the observed vibrational levels. Rotational constants $B_{e}$, $\alpha_{1}, \alpha_{3}, D_{e}, \beta_{1}, \beta_{3}$ and vibrational constants $\omega_{1}, \omega_{3}, x_{13}$ have also been obtained. The validity of the simplified Valence Force Field model seems to give agreement for $\omega_{1}$. But we need to get a more important data base to confirm the disagreement concerning $\omega_{3}$. Perturbations have been clearly shown both in the upper and lower vibrational levels of $2 \Pi_{\mathrm{u}}$ and $2 \Pi_{\mathrm{g} 3 / 2}$. They are certainely due to several possible perturbers $2 \Sigma_{\mathrm{g}}{ }^{+}$, $2 \Pi_{\mathrm{g} 1 / 2}, 2 \Delta_{\mathrm{g}}, 2 \Pi_{\mathrm{u} 1 / 2}, 2 \Sigma_{\mathrm{u}}{ }^{+}$but they have yet to be treated. We have also to understand the vibrational structure of the upper state $2 \Pi_{\mathrm{u}}$.

Acknowledgements: This work benefited fro : financial support from the Air Force Office of Scientific Research(grcr: AFOSR-91.0235) and from the Direction des Recherches, Etudes et Techniques(grant 901609/A000/DRETIDS/SR).

\section{References}

1/ J.T.Hougen, G.E.Leroi and T.C.James, J.Chem.Phys.34, (1961) 1670

2/ C.W.Bauschlicher and B.O.Roos ,J.Chem.Phys.91, (1989) 4785

3/ S.Yoshida, M.Taniwaki, T.Sawano, K.Shimizu and T.Fujioka ,J.App.Phys.Jpn 28 , (1989) L831

4/ T.Tokuda, N.Fujii, S.Yoshida, K.Shimizu and I.Tanaka ,Chem.Phys.Lett.174, (1990) 385

5/ N.N.Greewood and A.Earnshaur ,Chemistry of the elements, Pergamon,(1884) 931

6/ A.J.Rọss, R.Bacis, A.J.Bouvier, S.Churassy, J.C.Coste ,P.Crozet and I.Russier, ,J.Mol.Spect 158, (1993) 27

7/ P.Crozet,.J.C.Coste, R.Bacis, A.J.Bouvier, S.Churassy and A.J.Ross , Chem.Phys (accepted for publication)

8/ G.Herzberg ,Molecular Spectra and Molecular Structure ,vol 2 ,(Van Nostrand,N.Y., 1966)

9/ F.James and Roos, Comput.Phys.Commun.10 , (1985) 343

10/ J.E.Rosenthal , Phys.Rev.45, (1934) 426 